\title{
Práxis e formação em Psicologia Social Comunitária: exigências e desafios ético-políticos
}

\author{
Praxis and formation of Community \\ Social Psychology: Demands and \\ ethical-political challenges
}

Maria de Fatima Quintal de FREITAS

\section{Resumo}

Neste artigo apresenta-se uma breve contextualização a respeito de alguns desafios presentes à formação no campo da Psicologia e das práticas psicossociais em comunidade. A seguir desenvolve-se uma análise em torno de três eixos. No primeiro será feita uma exposição sobre o contexto atual e campo das práticas da Psicologia Social Comunitária, destacando-se preocupações e tensões nessas práticas. No segundo eixo, as dimensões teórico-metodológicas relevantes para o processo de formação serão indicadas e estão denominadas como "necessidades de formação para a práxis" em Psicologia Social Comunitária. No último eixo, apresentam-se o que se denominou de "delicadezas" ético-políticas presentes no "fazer" psicossocial em comunidade. Finaliza-se com a indicação de princípios e suas respectivas categorias conceituais, considerados necessários ao processo de formar para a práxis em Psicologia Social Comunitária.

Palavras-chave: Formação do psicólogo; Psicologia comunitária; Psicologia social.

\begin{abstract}
This article provides a brief contextualization of some challenges present in the formation within the field of psychology and of community psychosocial practices. An analysis is performed in three axes. The first axis describes the current context and field practices of Community Social Psychology, highlighting concerns and tensions found in these practices. The second points out the theoretical-methodological dimensions relevant for the formation process, which are denominated "formation needs for praxis" in Community Social Psychology. The last axis introduces the so-called ethical-policies "subtleties" that are part of the community psychosocial "work". Finally, principles and their concept categories necessary to the formation process of praxis in Community Social Psychology are presented.
\end{abstract}

Keywords: Pshychologist education; Communitty psychology; Social psychology.

$\nabla \nabla \nabla$

1 Universidade Federal do Paraná, Departamento de Teoria e Fundamentos da Educação, Programa de Pós-Graduação em Educação. R. General Carneiro, 460, Edif. Dom Pedro I, $1^{\circ}$ andar/PPGE, Centro, 80060-150, Curitiba, PR, Brasil. E-mail: <fquintal@terra.com.br>. 


\section{Paradoxos contemporâneos para a profissão psicologia: tensões na relação psicologia-universidade-sociedade}

Meados da segunda década do século XXI e passados 52 anos da constituição da profissão de psicologia, continuam presentes alguns aspectos, na relação profissão-universidade-sociedade. Destacam-se aqui, quatro deles.

Um primeiro aspecto situa-se na relação entre profissão consolidada e jovem, de um lado, e as repercussões disto para o processo de formação, de outro. Comparando-se com outros campos disciplinares, de fato a Psicologia pode ser considerada uma profissão relativamente jovem. Entretanto, isto não tem impedido que revele amadurecimento, em especial quando, diante dos problemas sociais, tem buscado ações e encaminhamentos na perspectiva psicólogica e psicossocial para uma melhoria nessas condições. Isto tem acontecido, por exemplo, em ações junto às chamadas políticas sociais, com intervenções dirigidas a diferentes estratos etários (crianças, jovens, adultos abandonados e/ou velhos), passando por programas junto a setores multiprofissionais na saúde e educação, até a implementação de propostas comunitárias de fortalecimento da redes de cooperação e participação, seja nas cidades ou no campo (Castro \& Correa, 2005; Flores Osório, 2011; Guzzo \& Lacerda Jr., 2011; Jímenez-Domínguez, 2008; Leite \& Dimenstein, 2013; Martinez, 2005; Yamamoto \& Gouveia, 2013). Estas possibilidades de trabalho em diferenciados contextos comunitários, há 30 anos poderiam ser vistas como inimagináveis, ou mesmo como pouco comuns há 20 anos. Esta variedade de ações da Psicologia tornou-se mais visível, devido também à intensidade dos acontecimentos político-sociais, nas últimas décadas, que the demandaram outras formas de atuar diante das problemáticas sociais. Desta forma, em consonância a vários autores, pode-se afirmar que não é esta possível juventude que torna a Psicologia menos forte e/ou menos consolidada. Ao contrário, e como apontam Oliveira e Yamamoto (2014), quando se referem ao primeiro cinquentenário da Psicologia, pode-se "concluir que se trata de uma profissão consolidada", visto que há hoje

522 um "grande número de profissionais graduados e credenciados" (p.17), ao lado do crescimento das produções científicas. Contudo, este caráter de consolidação não significa que já foram atingidas, nos cursos de graduação e pós-graduação em Psicologia, as metas quanto à plenitude da formação e preparação dos profissionais para que atuem e saibam fazê-lo, em estreita relação e compromisso social com a população que tem sido alvo de seus trabalhos.

Assim, ao lado desta jovialidade e de uma profissão já reconhecida e, em parte, consolidada, pode-se dizer que ainda são muitos os desafios, quais sejam: como formar, preparar e envolver os profissionais de Psicologia para atuarem de maneira comprometida com a realidade social? Como formá-los de tal modo que ultrapassem os modelos e paradigmas tradicionais, e possam construir novos paradigmas com base na realidade social concreta?

A cada nova formulação de políticas sociais e diante da ampliação de campos nos quais a Psicologia se insere, este parece ser um desafio perene que tem apresentado questões sérias ao processo de formação. Trata-se de um desafio implacável colocado a todos(as) aqueles(as) que se preocupam com o papel e compromisso sociais da profissão, entendendo-a como um fator importante, também, para a superação de formas de exclusão e injustiças sociais existentes no mundo e sociedade contemporâneos.

Um segundo aspecto liga-se à ampliação de campos e à diversidade temática quando da inserção. Isto coloca o debate sobre que conteúdos e que formas a prática profisisonal poderá ter: adotar "velhos" ou "novos" paradigmas para a sua ação? Surgem, aqui, outras preocupações ligadas ao tipo de formação que os cursos de Psicologia estariam promovendo e que poderiam resultar em mudanças importantes (Bastos \& Gondim, 2010; Oliveira \& Yamamoto, 2014). Ou seja, questiona-se sobre como contribuir, no processo formativo, para a construção de estratégias de ação que se comprometam com as problemáticas socialmente relevantes e necessárias na perspectiva da população.

Nos últimos 20 anos, mais especificamente quando surgiram propostas de implementação de políticas sociais e públicas que estivessem preocu- 
padas com a maioria da população, pode-se dizer que dois desafios importantes para a Psicologia foram colocados. Um deles liga-se ao fato de se ampliarem os cenários de inserção e atuação para o profissional de Psicologia, e o outro desafio, em parte decorrente do primeiro, refere-se à necessidade e expectativa de que a atuação seja diferente dos espaços e paradigmas tradicionais, utilizados nos campos mais conhecidos de atuação (como clínica, consultórios, e mesmo parte das escolas) (Martínez, 2005; Sandoval, 2000; Senra \& Guzzo, 2012; Silva, 1998).

Espera-se que esse profissional, em sua prática, atenda a três demandas: atue de maneira não mais individual e psicologizante; integre equipes de trabalho multiprofissional; e incorpore como objeto de investigação aqueles fenômenos sociais que pareciam pouco relevantes à psicologia tradicional. Estas demandas, por si só, apresentam desafios intrínsecos ao processo de formação, visto que a Psicologia, ao longo dos anos, trabalhou exatamente ao contrário. Em outras palavras, trabalhou de modo a adotar modelos de psicologização das relações e da vida cotidiana, além de ter se posicionado como se fosse um "sujeito único" hegemônico na sua prática, seja quando da produção de conhecimentos, seja quando das decisões sobre o quê fazer com o seu objeto de trabalho e investigação.

Deparamo-nos, então, com um paradoxo. De um lado, há um cenário rico em diversidades e temáticas para a atuação dos profissionais de psicologia, o que poderia contribuir para uma maior exigência de qualificação em sua formação para lidar com os problemas sociais. De outro, ainda presenciamos a manutenção de uma preparação frágil e compartimentalizada para lidar com esse tipo de prática, cujas exigências ultrapassam mais do que mudanças espaciais e geográficas na atuação. Essas exigências, em verdade, mostram a necessidade de que haja mudanças paradigmáticas e ontológicas que levem a apreender e compreender o objeto, da inserção e atuação dos profissionais de psicologia, dentro de uma relação compartilhada, horizontal, partícipe e histórico-dialética. Com isso estaria sendo garantida a coerência com os pressupostos epistemológicos ligados à construção de uma profissão socialmente relevante e comprometida com a superação dos problemas sociais com os quais trabalha.

Um terceiro aspecto, presente na relação profissão-universidade-sociedade, refere-se ao fato de que - acompanhando o movimento de ampliação e interiorização de universidades públicas no território nacional, em especial a partir de inícios deste século -, a Psicologia passou a fazer parte de cursos desenvolvidos em pequenas cidades, em contextos rurais e distantes dos grandes centros urbanos. Derivado deste deslocamento urbano-rural, apresenta-se também para a Psicologia o desafio de construir aportes teórico-metodológicos que aproximem a profissão aos cenários rurais, até então pouco reconhecidos em seus paradigmas tradicionais que sempre dirigiram-se a formar para uma prática psicológica e psicossocial nos centros urbanos. No centro desta tensão, surge um outro paradoxo. De um lado, nesses novos cenários do processo de interiorização, reinstala-se o fortalecimento do enfoque individual clínico visto que é uma forma de trabalhar consolidada e que traz ao profissional alguma segurança na sua prática diária. De outro, apresenta-se a necessidade de serem desenvolvidos outros aportes para conhecer a nova realidade no contexto rural e/ou das pequenas cidades, e poder atuar junto a essas novas e diferentes necessidades, e isto nem sempre foi desenvolvido nos cursos de formação.

$E$, o quarto aspecto que parece também importante nesta proposição de debate e reflexão, situa-se na relação tipo de instituição formadora e qualidade da formação, de um lado, e atualização e conhecimentos sobre a realidade concreta, de outro. Isto refere-se ao fato de que ainda temos um predomínio de escolas privadas $(82,23 \%$ das instituições de ensino superior) em que o curso de Psicologia é fornecido, sendo que dessas $63,44 \%$ (229 instituições particulares) situam-se nas regiões Sudeste e Sul do Brasil (Baima, 2014). Observa-se que a produção de pesquisas e projetos de extensão/ intervenção, assim como a atualização e desenvolvimento de estratégias metodológicas, concentram-se nas universidades públicas e, ainda, nos centros urbanos maiores e com mais recursos e desenvolvimento científico atualizado. Embora, a 
ampliação e interiorização dos cursos tenha menos de 15 anos, sabe-se que a produção de conhecimento liga-se fortemente à pós-graduação que, ainda, se concentra nas maiores e mais antigas instituições de ensino superior, geralmente de caráter público e localizadas nos centros urbanos maiores. Assim, o que se presencia é que a maioria dos cursos de Psicologia, ministrados em instituições privadas ou em públicas no interior do país, ainda estão distantes dos centros de investigação e dos pólos de produção de conhecimento. Reinstala-se um forte desafio: de um lado, ampliaram-se os cursos de Psicologia, a tal ponto que em 2014 existem 449 cursos no território nacional (Baima, 2014) e, de outro, pouca garantia há de que tais cursos estejam sendo diferentes dos paradigmas tradicionais que deram origem à profissão no seu início.

Pode-se, então, perguntar sobre o que existiria entre a Psicologia e as políticas sociais ou, mais especificamente, entre as práticas da Psicologia Social Comunitária (PSC) e as propostas da sociedade civil para o atendimento das necessidades principais da maioria da população? Este ainda é um debate atual localizado na discussão sobre as relações Profissão e Sociedade, atravessadas pelo processo de formação (Guzzo \& Lacerda Jr., 2011; Yamamoto \& Gouveia, 2013). Quão distantes ou quão próximas ambas estariam e como isto poderia afetar a vida das pessoas nos espaços sociais em que vivem e atuam?

Após esta breve contextualização a respeito de alguns desafios à formação, propõe-se, neste artigo, tecer uma análise em torno de três eixos. No primeiro eixo, far-se-á uma breve exposição a respeito do contexto atual e campo das práticas da PSC, destacando-se algumas preocupações e tensões em tais práticas. No segundo eixo, serão indicadas as dimensões teórico-metodológicas consideradas relevantes para o processo de formação, e que estão sendo, aqui, denominadas de "necessidades de formação para a práxis" em PSC. E no último eixo, apresentar-se-ão o que aqui se chama de "delicadezas" ético-políticas presentes no "fazer" psicossocial em comunidade e na relação comunidade-profissionais, finalizando com a indicação de princípios considerados necessários ao processo de formar

\section{Eixo I: Contexto atual e campo das práticas da Psicologia (Social) Comunitária}

No início do século XXI, ainda antes de completar 40 anos, a Psicologia presenciou um aumento significativo de suas propostas de trabalho no campo das práticas comunitárias (Alfaro, Sánchez, \& Zambrano, 2012; Freitas, 2005; 2007; 2011b; Montero, 1994; 2003; Montero \& Serrano-Garcia, 2011). Em decorrência, as publicações no campo da Psicologia (Social) Comunitária passaram a ter mais visibilidade trazendo à tona dois aspectos importantes. O primeiro aspecto refere-se ao aumento de propostas e práticas, em um campo que poderia ser chamado de Psicologia (Social) Comunitária, se se levar em conta dois elementos diferenciadores e interdependentes entre si. Esses elementos mostram que as ações passaram a ser realizadas fora dos espaços tradicionais (consultórios e empresas, por exemplo) de uma maneira diferente àquela defendida pelos paradigmas hegemônicos dominantes na Psicologia; e que as ações psicossociais em comunidade revelaram um forte compromisso com os setores populares na busca de melhorias para o cotidiano desses segmentos. O segundo aspecto está relacionado ao fato de que existe, hoje, uma grande diversidade de inserções e práticas psicossociais (Alfaro et al., 2012; Almeida Acosta, 2011; Montero \& Serrano-Garcia, 2011; Sarriera, 2000) que, ao lado de outros campos disciplinares, têm se mostrado importantes para o enfrentamento das problemáticas vividas pelos diferentes grupos e comunidades (Freitas, 1998).

Presencia-se, assim, hoje, uma alta variedade no campo da PSC. Há uma diversidade de práticas, fazeres, referenciais teóricos, instrumentais utilizados, temáticas focalizadas e privilegiadas para as ações, de proposições distintas mesmo que para dinâmicas e contextos comuns, recursos empregados para reunir e mobilizar grupos e comunidades, entre tantas outras formas de atuar (Flores Osorio, 2007; 2011; Freitas, 2011a; 2012). Nos últimos anos, começou a ser comum dizer que, podem ser vistos como práticas da Psicologia (Social) Comunitária, aqueles trabalhos que tivessem algumas características como: serem realizados fora dos 
consultórios e gabinetes de trabalho; serem executados nas ruas das cidades ou nas vilas e cenários camponeses; envolverem um número maior de pessoas e grupos; defenderem relações horizontais e não hierárquicas; utilizarem também recursos das expressões artístico-musicais e da criatividade humana, entre outros. Some-se, aqui, também, o fato de que os trabalhos que se refiram a qualquer problema social concreto, a qualquer dificuldade enfrentada no cotidiano pelas pessoas, e que tenham alguma proposta de melhoria dirigida aos setores desfavorecidos, oprimidos e excluidos, também, poderiam ser vistos como formas de trabalho da Psicologia (Social) Comunitária.

Entretanto, neste momento, o que se pode, de fato afirmar, é que estas situações e constatações estampam, de maneira clara, uma tensão do ponto de vista conceitual entre o que é, de fato, essência e o que é aparência neste campo das práticas da Psicologia (Social) Comunitária.

Assim, há um debate necessário sobre o que é essencial e singular nesse tipo de práxis (Flores Osorio, 2011; Freitas, 2005; 2012; Gaborit, 2011; Martín-Baró, 1987). E, que elementos aparenciais podem estar existindo e contribuindo para que fiquem nebulosas as fronteiras entre a práxis da PSC e a de outras formas de trabalhar em Psicologia, mesmo que todas aconteçam em contextos e dinâmicas comunitárias. Três elementos emergem neste debate, considerando-se esta maior aproximação entre as práticas psicossociais em comunidade e os diferentes setores populares. O primeiro é de que não há uma base consensual que mostre haver igualdades teórico-conceituais entre tais práticas. O que se pode afirmar sobre o que é comum e consensual nos vários trabalhos situa-se, muito mais, no fato de que as propostas de intervenção comunitária dirigem-se a algum problema social, a alguma dificuldade vivida pela população em seu cotidiano e a alguma proposta de melhoria. Deriva-se daí um segundo aspecto, ligado à necessidade de serem feitas análises epistemológicas rigorosas que levem a um desmonte das pseudo-conciliações entre bases ontológicas e orientações metodológicas presentes nos vários trabalhos comunitários. Pode-se dizer que pouco têm sido analisadas, nos diferentes trabalhos em comunidade, essas diferenças e incoerências epistemológicas e ontológicas das práticas. Um terceiro fator refere-se à necessidade da análise sobre o grau de impacto e importância que essas práticas têm, no sentido de se são de fato práticas imprescindíveis à vida e cotidiano comunitários. Promover esta discussão, em nosso entendimento, significa falar dos caminhos da práxis da PSC, o que implica necessariamente desvelar os fundamentos do processo de politização da consciência que está diretamente ligado à participação da própria população em torno de suas necessidades concretas, mediatas e imediatas.

Tomando-se como referência isto, algumas perguntas poderiam ser feitas a respeito das relações entre práxis e formação questionando-se, também, o tipo de compromisso e ética envolvidos. Vejamos algumas indagações mais urgentes e atuais: a) haveria alguma especificidade (seja política, instrumental e/ou teórica) para que se pudesse atuar neste campo? b) qualquer psicólogo(a) poderia atuar em PSC? c) outras profissões poderiam atuar em PSC? e d) que diferenças há, por exemplo, entre o(a) educador(a) popular/comunitário(a), o(a) trabalhador(a) social, o(a) assistente social, somente para se falar de alguns? Todas estas questões parecem levar a duas grandes reflexões e desafios centrais que seriam: como formar para a intervenção (prática) psicossocial em comunidade? E, como formar para ter um compromisso com a transformação social?

Podemos, então, nos perguntar se seria isto possível, ou se isto poderia estar fora do âmbito da formação e capacitação profissionais. No caminho de intentar refletir a respeito destes grandes desafios, seja para o campo da PSC seja para o próprio processo de formação, discutir sobre os aportes teórico-metodológicos fundamentais e sobre os cuidados ético-políticos da prática parecem importantes. Cada um deles estarão sendo desenvolvidos nas seções seguintes.

\section{Eixo II: Aportes teórico-metodológicos necessários à formação em Psicologia Social Comunitária}

Os problemas relativos à injustiça, à pobreza e ao sofrimento humano, assim como seus 
determinantes estruturais e conjunturais, podem continuar a existir e, infelizmente, têm continuado mesmo em sociedades altamente democráticas, como bem mostra a nossa história contemporânea (Freitas, 2014, p.66).

Indagações relativas ao que fazer para colaborar com um mundo mais justo e digno continuam sendo fortes desafios colocados a qualquer tipo de prática e ao processo de formação de diferentes profissionais no mundo atual (Ferrarini, 2008; Hobsbawn, 2000). Entretanto, há que se evitar uma armadilha interna a esse processo presente, hoje, a quase todas as áreas envolvidas com os chamados projetos sociais e comunitários. Esta armadilha aparece em relação ao que já se denominou, em outra ocasião, de "mito da mão estendida" (Freitas, 2005), que se refere ao fato de que, hoje, seria politicamente incorreto não estar fazendo qualquer trabalho, social ou voluntário, de ajuda ao próximo. Poder-se-ia perguntar onde estaria essa armadilha. Com certeza não é no fato de se fazer algo, em prol dos outros. A armadilha estaria na idéia de que: 1) fazer algo imbuído de boas intenções seria suficiente para uma possível melhoria social, e 2) que a "boa vontade" nesse fazer poderia substituir uma "profissionalização", séria e comprometida, dessa ação. Entenda-se esta "profissionalização" como os aportes teóricos e metodológicos necessários para uma ação profissional comprometida, que possa ter continuidade, história coletiva e memória social para que sejam transmitidos os conhecimentos e produções humanas, próprios daquele fazer profissional, no nosso caso, o fazer psicossocial em comunidade.

Quando se pergunta sobre que aportes teórico-epistemológicos são necessários para a formação em PSC, surgem preocupações ligadas a: como captar a vida real dos chamados excluídos que muitas vezes tornam-se "invisíveis" sociais para a investigação, visto que são considerados "pouco significativos" segundo os parâmetros científicos e estatísticos? Este é o caso, por exemplo, dos jovens pobres de periferia que sobrevivem psicossocialmente a despeito de todas as tragédias e adver- caso das pessoas velhas "ativas" que, por isso mesmo, fogem à regra de serem incapazes e decrépitas, uma vez que estão a realizar inúmeras atividades como qualquer pessoa de outra faixa etária menor, só que chegam a ser desconsideradas para estudos ou programas comunitários por não serem "representativas". Instaura-se, assim, um desafio importante para o processo de formação no campo da PSC. Como compreender os diferentes atores sociais, dentro de sua própria realidade, sem se distorcer a concretude histórica de sua vida cotidiana, sem cair no paternalismo ou assistencialismo; e mantendo a coerência aos princípios da PSC na direção do fortalecimento e da construção de redes de convivência mais solidárias, justas e dignas no cotidiano das pessoas?

Isto coloca o desafio conceitual e ontológico ligado a: como conseguir captar a concretude histórico-social das relações humanas - determinadas estrutural e conjunturalmente, e vividas em sua cotidianidade singular e genérica (Heller, 1982; Paulo Netto \& Carvalho, 1996) -, de tal modo que seja fiel à dinâmica e contexto comunitários?

São seis as necessidades consideradas importantes ao processo formativo neste campo e que permitem compreender três aspectos: os compromissos estabelecidos pelos agentes comunitários (internos e externos), os resultados produzidos pela intervenção comunitária, e os diferentes níveis de participação nas atividades realizadas. Estas necessidades permitiriam compreender os diferentes processos psicossociais de participação e conscientização, seja da comunidade, seja dos profissionais.

Assim, apresentam-se, a seguir como indicado na Figura 1, as denominadas seis necessidades para poder formar para a práxis em Psicologia Social Comunitária.

Na necessidade 1, da dimensão epistemológica, é importante o conhecimento histórico-crítico a respeito da construção sócio-política da vida cotidiana dos diferentes grupos e comunidades com os quais se pretende trabalhar, relacionando-o às dimensões local, regional e global. Isto contribuirá para uma análise contextualizada e para a compreensão histórica sobre os determinantes es- 


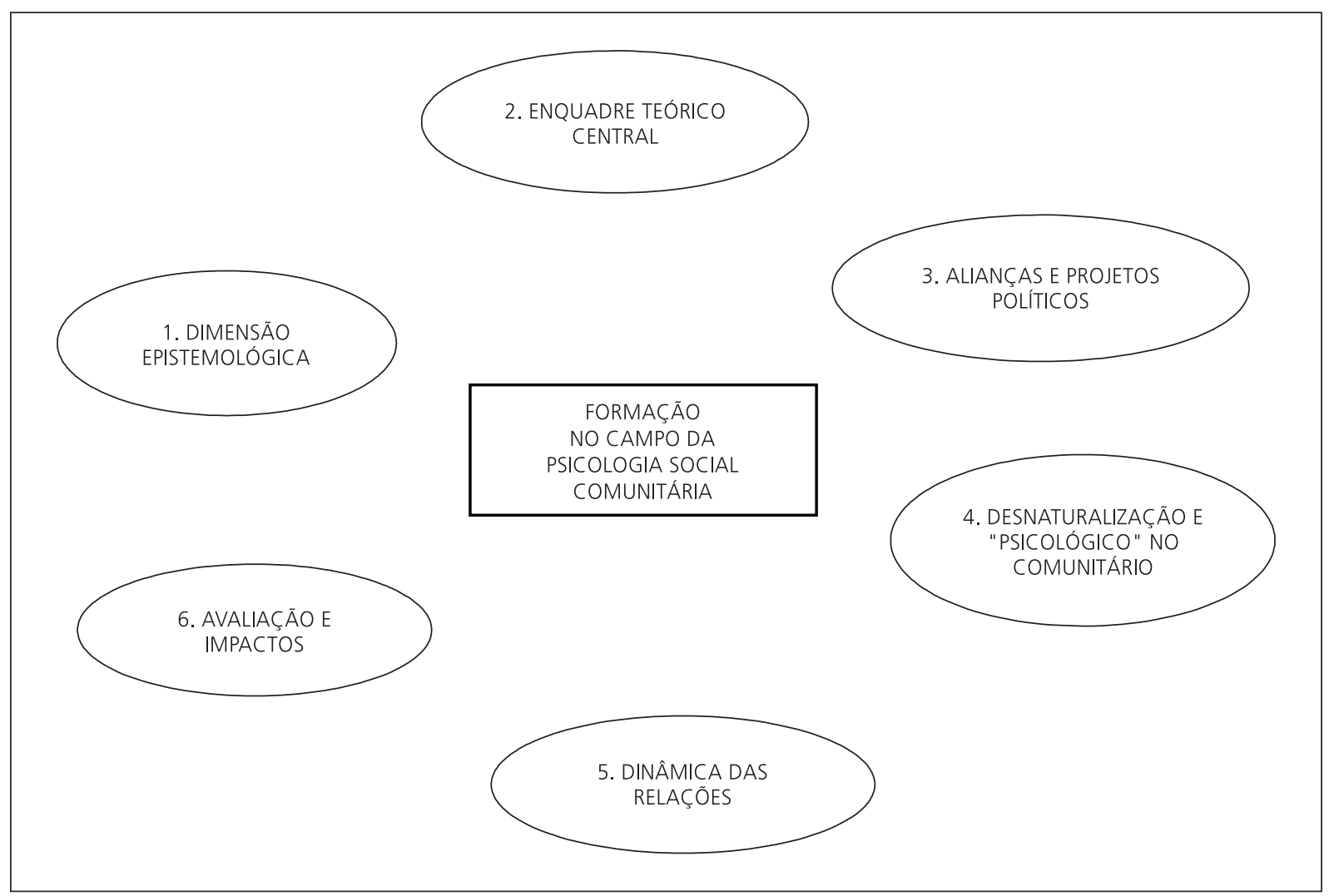

Figura 1. Seis necessidades da formação para a práxis em Psicologia Social Comunitária.

truturais e conjunturais da dinâmica e contexto comunitários.

Na segunda necessidade, a do enquadre conceitual principal, é imprescindível que os cotidianos de existência das pessoas e as redes de convivência comunitária construídas sejam tomados como matriz principal, nos trabalhos comunitários. Isto significa compreender a vida dessas pessoas em várias dimensões, interligadas e interdependentes: nos seus problemas cotidianos, nas suas possibilidades de enfrentamento, nos seus projetos de utopia para a sociedade, e na construção de ações coletivas e comunitárias. Significa, no plano psicossocial, realizar uma análise conjuntural e estrutural no plano psicossocial, que ultrapasse explicações reducionistas, psicologizantes e pontuais, e que permitam ver o futuro como um projeto político-pedagógico de transformação e de utopia a serem buscados de maneira coletiva e partícipe.

Na terceira necessidade, relativa às alianças e aos projetos políticos, faz-se necessário compreen- der como se articulam e se comprometem os diferentes movimentos sociais, grupos comunitários e diversos segmentos da sociedade, em torno de uma proposta coletiva e voltada a fins coletivos e solidários.

A quarta necessidade, a da desnaturalização da vida cotidiana e concepção sobre o que é o fenômeno psicológico na dinâmica comunitária, liga-se a como fazer com que as pessoas acreditem que vale a pena, também, participar, nas esferas públicas e coletivas, como sendo uma condição importante para o fortalecimento das redes e projetos comunitários. E, também, refere-se às concepções e compreensões que os agentes comunitários têm a respeito do que é e não é um fenômeno psicológico, nas diferentes dinâmicas comunitárias, e como tudo isso poderia impactar os trabalhos realizados. Isto pode permitir entender os diferentes caminhos que os trabalhos comunitários têm, de avanço ou recuo, remetendo-os também às (in)coerências dos recursos metodológicos empregados. 
A compreensão da dinâmica das relações do trabalho comunitário - quinta necessidade -, referese às ferramentas utilizadas e ao "olhar" construído para compreender o que se passa na vida cotidiana de tais práticas envolvendo todos os atores sociais (Freitas, 2003; 2005; 2009; 2011a). Isto significa compreender as: a) razões para realização do trabalho (para comunidade, profissionais, stakeholders, agências governamentais, etc.); b) relações entre agentes internos e tipo de participação construída entre eles; e c) características da prática desenvolvida e frutos obtidos.

A última necessidade, da avaliação e impactos das práticas em comunidade, refere-se a construir recursos e ferramentas, colaborativas e participativas, de avaliação. Eles devem ser específicos a cada contexto e dinâmica, com a finalidade de saber se o trabalho é, de fato, prioritário e imprescindível; se estaria atendendo a que necessidades e de quem; se traria mudanças relevantes e, se as produzisse seria na perspectiva de quem.

\section{Eixo III: Dimensões ético-políticas e princípios da práxis em Psicologia Social Comunitária}

Neste momento, faz sentido perguntar sobre o que, aqui, se denomina de "delicadezas" ético-políticas que estão presentes no "fazer" psicossocial em comunidade e na relação comunidade-profissionais.

Pode-se dizer que essas "delicadezas" se referem a dois âmbitos. No primeiro, relativo à implementação e realização das ações comunitárias (ao fazer psicossocial em comunidade), pode-se perguntar sobre os cuidados éticos que devemos ter. Isto pode ser traduzido em indagações como: a) posso (ou não) e devo atuar (ou não) de uma dada maneira em situações, por exemplo, de violência, de preconceito, de exclusão? e b) com quem me comprometo e explicito meu envolvimento político-social? Estas questões remetem a um debate sobre o paradigma da responsabilidade e do quão justa uma ação pode ser, em um dado contexto em que acontece, discussão esta apresentada em trabalhos "delicadeza" ético-política, encontram-se as relações e parcerias entre profissionais e comunidade (Freitas, 1998; 1999; 2011a) e, hoje, mais contemporaneamente, também com os stakeholders e políticas públicas (Freitas, 2014; Guzzo, Mezzalira, \& Moreira, 2014). Isto aparece em questionamentos como: a) que tipo de relação se estabelece entre esses três personagens?, b) que relação de conhecimento e de autoridade travam entre si?, e c) quem e como são definidos os objetivos e rumos do trabalho?

A discussão sobre o que se apresenta como necessário para formar para a práxis em PSC - quanto aos aportes teórico-metodológicos e às delicadezas ético-políticas -, cada vez mais revela uma preocupação, presente nos cursos de formação nos últimos anos, com relação a dois aspectos. Um, se os cursos estão, de fato, formando e capacitando, cien-tífica e politicamente, os futuros profissionais para desenvolverem intervenções e programas comunitários. Fala-se, aqui, então da dimensão do "saber fazer", pertinente a todos os agentes envolvidos na bipolaridade do processo de aprendizagem e formação. O segundo aspecto, numa íntima relação dialética com o primeiro, liga-se a como implementar e colaborar para o surgimento de uma sensibilidade histórica e identificação política desses profissionais para com a população, sensibilidade essa guiada por um compromisso com a transformação social.

O que seria, então, necessário e importante para poder formar para a práxis em Psicologia Social Comunitária? Apresentam-se, na Tabela 1, os princípios e suas respectivas categorias conceituais que deveriam ser contemplados no processo de formação, a fim de se constituirem como guias norteadores para a práxis em PSC.

Um primeiro é o que se denomina aqui de compreensão conjuntural e estrutural dos modos de (re)produção da existência humana, compreendida necessariamente como uma construção social da realidade e vida cotidianas, como desenvolveram e aprofundaram Berger e Luckmann (1983); Heller (1982); Lane (1984); Lukács (2012); Martín-Baró (1987); Marx (1970). A leitura crítica e compreensão dos princípios fundantes da vida societal, ao lado 
Tabela 1

Cinco princípios norteadores e respectivas categorias conceituais para formar para a práxis em Psicologia Social Comunitária

\begin{tabular}{|c|c|}
\hline Princípios & Categorias conceituais e dimensões envolvidas \\
\hline $\begin{array}{l}1 \text { Análise conjuntural e estrutural sobre a (re)produção da exis- } \\
\text { tência humana. }\end{array}$ & $\begin{array}{l}\text { Construção social da vida cotidiana. } \\
\text { Fundamentos da vida societal. } \\
\text { Impactos nos processos psicossociais. } \\
\text { Conhecimentos inter e multidisciplinares sobre relações humanas e sociais. }\end{array}$ \\
\hline 2 Conhecimentos inter e multidisciplinares e trabalho coletivo. & $\begin{array}{l}\text { Aportes da educação popular (de Paulo Freire). } \\
\text { Aportes da investigação-ação-participante (Orlando Fals Borda). } \\
\text { Processos grupais. } \\
\text { Pressupostos do trabalho comunitario coletivo. }\end{array}$ \\
\hline 3 Caráter pedagógico da formação e politização no cotidiano. & $\begin{array}{l}\text { Compromisso social e político com os oprimidos. } \\
\text { Processos de participação e conscientização. } \\
\text { Desnaturalização da vida cotidiana ('despsicologização' e 'despatologização' } \\
\text { da vida cotidiana e das relações sociais). }\end{array}$ \\
\hline 4 Construção participativa de objetivos a posteriori. & $\begin{array}{l}\text { Relações horizontais, partícipes e dialógicas. } \\
\text { Conhecimento popular e profisssional com mesmo status social e científico. } \\
\text { Ferramentas e instrumentos colaborativos e participativos. }\end{array}$ \\
\hline 5 Avaliação da população ao trabalho realizado. & $\begin{array}{l}\text { Caráter temporário do trabalho. } \\
\text { (Des)continuidade da prática. }\end{array}$ \\
\hline
\end{tabular}

de como isso impacta na construção dos processos psicossociais, no plano microssocial e macrossocial, são condições determinantes para a constituição dos aportes necessários à práxis em PSC.

Um segundo princípio, derivado e relacionado ao anterior, liga-se a uma práxis baseada em conhecimentos ampliados, provenientes também de outros campos disciplinares e colaborando para que as produções, teóricas e práticas, sejam inter e multidisciplinares. Para isso, alguns aportes são essenciais, como os da educação popular, baseada em Paulo Freire (Assumpção, 2009; Barreiro,1985; Freitas, 1999; 2007; 2012) e os da investigação-ação-participante, apoiada na perspectiva de Orlando Fals Borda (Brandão \& Assumpção, 2009; Fals Borda, 1986). Agrega-se também o fato de que ter uma práxis assentada nestes conhecimentos e valores exige que o trabalho seja, necessariamente, realizado em equipe e de maneira coletiva e comunitária. Deriva, então, a necessidade de se saber trabalhar em grupo e com os processos psicossociais em grupo (Lane, 1984; Martín-Baró, 1987), como agentes internos e externos nas práticas comunitárias.

O terceiro princípio, aqui chamado, caráter pedagógico de formação e politização no cotidiano, envolve duas dimensões: a do compromisso com os segmentos populares explorados e oprimidos, e a do fortalecimento dos processos de participação e conscientização que se materializam na vida cotidiana, que deve ser compreendida e vivida fora dos mecanismos e explicações naturalizantes e fragmentadores. Isso significa contribuir para análises que primem pelas categorias da totalidade e contradição históricas, contribuindo para que se faça uma 'despsicologização' ou 'despatologização' da vida cotidiana e das relações sociais, e eliminando os processos ligados ao fatalismo e à crença na imutabilidade e irreversibilidade históricas.

A forma de construção dos objetivos, referentes à prática comunitária, trata do quarto princípio importante e definidor dos rumos do trabalho. Se esses objetivos, de fato, forem discutidos e construídos de maneira participativa e colaborativa entre comunidade e profissional, a sua configuração e o processo de construção acontecerá de maneira a posteriori e participativa (Freitas, 1998; 1999), levando em conta as necessidades básicas, sentidas e vividas, da população. Isto se aproxima àquilo que Freire (1976) denominou de relação dialógica em que ambos, na relação estabelecida, ocupam, ao mesmo tempo, o lugar de sujeitos e objetos do conhecimento. No caso da PSC, ambos - comuni- 
dade e profissionais -, tornam-se, a todo momento, sujeitos e objetos do próprio processo de construção dos conhecimentos sobre a vida e dinâmica comunitárias. Derivado disto podem ser construídas metodologias participativas e colaborativas, mantendo-se a coerência a estes pressupostos, em que o conhecimento popular e o conhecimento científico, como defendia Fals Borda (1986), situam-se num mesmo patamar de status e reconhecimento social e científico.

Um último princípio liga-se à avaliação da população a respeito da prática dos profissionais envolvidos. Aparecem, de maneira forte, as dimensões da temporalidade do trabalho e sua continuidade que ficam na dependência direta dos crivos e resultados da avaliação que a comunidade faz. Ou seja, o trabalho poderá continuar ou não, dependendo do grau de importância e impacto sentidos e valorizados pela população. Encontra-se aqui um dos aspectos que mostram haver (ou não) coerência e, de fato, horizontalidade na relação entre profissionais e comunidade.

A questão relativa a como se poderia ensinar e aprender estas dimensões e princípios, para que se constituissem em diretrizes para a práxis em PSC, continua sendo um grande desafio e meta colocada a todos(as) os(as) profissionais e cursos que compreendem a profissão como devendo ter um íntimo compromisso com a mudança e transformação social.

Não é o fato de, na prática profissional a ser realizada, haver um envolvimento, identificação e compromisso com setores precarizados, que essa prática teria a autorização de ser feita, também, de modo precarizado e "menos", ou seja, de uma forma subvalorizada, subqualificada e subformada. Fazer isso seria legitimar, de maneira subliminar e através de uma prática profissional 'mal feita', as injustiças e desigualdades sociais. Exatamente o contrário é o que se defende, até porque deveriam ser construídos, com uma exigência científico-profissional maior, mais conhecimentos, recursos e estratégias para eliminar essas condições de injustiça e indignação em que a população vive.

Melhor, então, seria se pudessem existir pro$\mathbf{5 3 0}$ fissionais altamente qualificados, juntamente com um compromisso político e social para com os setores e grupos explorados e oprimidos. E, para isso, propõe-se que no processo de formação algumas ações deveriam buscar enfrentar os desafios relativos a seis condições, quais sejam: a) efetivar propostas de trabalhos interdisciplinares; b) elaborar e planejar de maneira participativa programas de políticas públicas em que a comunidade seja o foco das ações; c) encontrar critérios importantes na perspectiva comunitária para que sejam implementadas investigações relevantes; d) como trabalhar em grupo e diminuir a fragmentação da realidade; e) como criar estratégias de avaliação continuada das práticas desenvolvidas, e f) como construir programas comunitários que envolvam toda a comunidade.

Em consonância à crença de que é a vida concreta que nos ensina a fazer mudanças nas relações, defende-se que algumas condições concretas deveriam contribuir para um aprofundamento na qualidade da formação dos (as) profissionais. Assim, se de um lado, não é a exigência profissional e científica que, por si só, vai produzir mudanças, também a ausência de qualidade e de exigências formativas pode colaborar para que haja uma precarização e distanciamento de compromissos para com uma vida mais justa para os setores que são alvo de nossas práticas. Em outras palavras, subestimar as exigências de qualificação e precarizar as condições de formação e capacitação profissionais, também servem para legitimar e quase naturalizar que não seria possível mudar e melhorar a formação profissional em nossa área e, consequentemente, contribuir com mudanças sociais.

\section{Referências}

Alfaro, J., Sánchez, A., \& Zambrano, A. (Comp.). (2012). Psicología comunitária y políticas sociales: reflexiones y experiencias. Buenos Aires: Paidós.

Almeida Acosta, F. H. E. (Ed.). (2011). International Community Psychology: Community approaches to contemporary social problems (Vol.1). Puebla: Universidad Iberoamericana de Puebla.

Assumpção, R. (Org.) (2009). Educação popular na perspectiva Freiriana (Série Educação Popular, Vol.3). São Paulo: Instituto Paulo Freire. 
Baima, L. S. (2014). Limites e possibilidades na contribuição para a mudança social: uma avaliação da formação em psicologia social comunitária no Brasil (Dissertação de mestrado não-publicada). Pontifícia Universidade Católica de Campinas.

Barreiro, J. (1985). Educacion popular y proceso de concientizacion (10 ${ }^{\mathrm{a}} \mathrm{ed}$.). Mexico: Siglo Veintiuno.

Bastos, A. V. B., \& Gondim, S. M. G. (Orgs.). (2010). O trabalho do psicólogo no Brasil. Porto Alegre: Artmed.

Berger, P. L., \& Luckmann,T. (1983). A construção social da realidade ( $5^{\mathrm{a}}$ ed.). Petrópolis: Vozes.

Brandão, C. R., \& Assumpção, R. (2009). Cultura rebelde: escritos sobre a educação popular ontem e agora. São Paulo: Instituto Paulo Freire.

Castro, L. R., \& Correa, J. (Org.). (2005). Juventude contemporânea: perspectivas nacionais e internacionais. Rio de Janeiro: Nau-Faperj.

Fals Borda, O. (1986). Conocimiento y poder popular. Colombia: Siglo Veintiuno.

Ferrarini, A. V. (2008). Pobreza: possibilidades de construção de políticas emancipatórias. São Leopoldo: Oikos.

Flores Osorio, J. M. (Coord.) (2007). Psicología, globalización y desarrollo en America Latina. México: Editorial Latinoamericana.

Flores Osorio, J. M. (Coord.) (2011). Psicología y práxis comunitária: Una visión latinoamericana. México: Editorial Latinoamericana.

Freire, P. (1976). Educacion y cambio. Santiago: Busqueda.

Freitas, M. F. Q. (1998). Inserção na comunidade e análise de necessidades: reflexões sobre a prática do psicólogo. Psicologia: Reflexão e Crítica, 11(1), 175-189.

Freitas, M. F. Q. (1999). O quê fazer? Reflexões em Psicologia Social Comunitária. In P. R. M. Menandro, Z. A. Trindade, \& E. B. Borloti (Orgs.), Pesquisa em Psicologia: recriando métodos (pp.105-124). Vitória: UFES.

Freitas, M. F. Q. (2003). Psychosocial practices and community dynamics: Meanings and possibilities of advance from the perspective of the engaged social actors. The International Journal of Critical Psychology, 9, 107-124.

Freitas, M. F. Q. (2005). (In)coerências entre práticas psicossociais em comunidade e projetos de transformação social: aproximações entre as psicologias sociais da libertação e comunitária. Psico, 36(1), 47-54.

Freitas, M. F. Q. (2007) Educação de jovens e adultos, educação popular e processos de conscientização: intersecções na vida cotidiana. Educar em Revista (Impresso), 1, 47-62.

Freitas, M. F. Q. (2008). Red de tesnsiones en la vida cotidiana: análisis desde la perspectiva de la psicología social comunitária. In B. Jimenez-Dominguez (Comp.),
Subjetividad, participación e intervención comunitária: una vision critica desde América Latina (Tramas sociales, n51, pp.165-183). Buenos Aires: Paidós.

Freitas, M. F. Q. (2009). ?(Des)encuentros entre la intervención y investigación comunitárias? Dilemas éticos en la perspectiva de la Psicología Social Comunitária. In C. Vazquez Rivera, D. Perez Jimenez, M. Figueroa Rodriguez, \& W. Pacheco Bou (Eds.), Psicologia Comunitaria Internacional: agendas compartidas en la diverdad (pp.151-179). San Juan, Porto Rico: Editorial Actividades de Formación Comunitaria.

Freitas, M. F. Q. (2011a). Construcción y consolidación de la psicología social comunitária en Brasil: conocimientos, prácticas y perspectivas. In M. Montero \&I. Serrano-Garcia (Comps.), Histórias de la psicología comunitária em America Latina. Participación y transformación (pp.91-114). Buenos Aires: Paidós.

Freitas, M. F. Q. (2011b). Community social psychology as political education and awareness-raising resistences and possibilities in everiday life: Suggestions for a model of analysis. In F. H. E. Almeida Acosta (Ed.), International Community Psychology: Community approaches to contemporary social problems (Vol.1, pp.73-94). Puebla: Universidad Iberoamericana de Puebla.

Freitas, M. F. Q. (2012). Prácticas de intervención comunitaria y políticas publicas: aproximaciones y límites desde la perspectiva de la psicología social comunitária latinoamericana. In J. Alfaro, A. Sánchez, \& A. Zambrano (Comps.), Psicología comunitária y políticas sociales: reflexiones y experiencias (pp.173-197). Buenos Aires: Paidós.

Freitas, M. F. Q. (2014). Expansão das práticas de intervenção comunitária: que horizontes para a psicologia social comunitária? In J. M. Flores Osório (Coord.), Repensar la psicología y lo comunitário en América Latina (pp.47-68). Tijuana, México: Universidad de Tijuana.

Gaborit, M. (2011). Memória histórica: reverter a história a partir das vítimas. In R. L. S. Guzzo \& F. Lacerda Jr. (Orgs.), Psicologia social para a América Latina: o resgate da psicologia da libertação (pp.245-276). Campinas: Alínea.

Guzzo, R. S. L., \& Lacerda Jr., F. (Orgs.) (2011). Psicologia social para América Latina: o resgate da psicologia da libertação ( $2^{a}$ ed.). Campinas: Alínea.

Guzzo, R. S. L., Mezzalira. A. S. C., \& Moreira, A. P. G. (2014). Desafios, ameaças e compromissos para os psicólogos: as políticas públicas no campo educativo. In I. F. Oliveira \& O. Yamamoto (Orgs.), Psicologia e Politicas Sociais: temas em debate (pp.215-238). Belém: UFPA.

Heller, A. (1982). La revolución de la vida cotidiana. Barcelona: Ediciones Península. 
Hobsbawm, E. J. (2000). Homo globalizatus. In E. J. Hobsbawm. O Novo Século: entrevista a Antonio Polito (pp.126-151). São Paulo: Companhia das Letras.

Jímenez-Domínguez, B. (Comp.). (2008). Subjetividad, participación e intervención comunitária: una vision critica desde América Latina (Tramas sociales, nº 51). Buenos Aires: Paidós.

Lane, S. T. M. (1984). A Psicologia Social e uma nova concepção do homem para a Psicologia. In A. T. M. Lane \& W. Codo (Orgs.), Psicologia Social: o homem em movimento (pp.10-19). São Paulo: Editora Brasiliense.

Leite, J. F., \& Dimenstein, M. (Orgs.). (2013). Psicologia e contextos rurais. Natal: EDUFRN.

Lukács, G. (2012). Para uma ontologia do ser social I. São Paulo: Boitempo.

Martín-Baró, I. (1987) El latino indolente: caráter ideológico dei fatalismo latinoamericano. In M. Montero (Coord.), Psicología Política Latinoamericana (pp.135-162). Caracas: Editorial Panapo.

Martínez, A. M. (Org.) (2005). Psicologia escolar e compromisso social. Campinas: Alínea.

Marx, K. (1970). Contribución a la crítica de la economia política. Madrid: Alberto Corazón.

Montero, M. (1994). Un paradigma para la Psicología Social: reflexiones desde el quehacer en America Latina. In M. Montero (Org.), Construcción y crítica de la psicología social (pp.27-48). Barcelona: Editorial Anthropos.

Montero, M. (2003). Relatedness as the basis for liberation. The International Journal of Critical Psychology, 9, 61-74.
Montero, M., \& Serrano-Garcia, I. (Comps.). (2011). Histórias de la psicología comunitária em America Latina: participación y transformación. Buenos Aires: Paidós.

Oliveira, I. F., \& Yamamoto, O. (2014). Apresentação. In I. F. Oliveira \& O. Yamamoto (Orgs.), Psicologia e Políticas Sociais: temas em debate (pp.17-20). Belém: UFPA.

Paulo Netto, J., \& Carvalho, M. C. B. (1996). Cotidiano: conhecimento e crítica ( $4^{\mathrm{a}} \mathrm{ed}$.). São Paulo: Cortez.

Sandoval, S. (2000). O que há de novo na Psicologia Social Latinoamericana? In R. H. F. Campos \& P. A. Guareschi (Orgs.), Paradigmas em psicologia social: a perspectiva Latinoamericana (pp.101-109). Petrópolis: Vozes.

Sarriera, J. C. (Org.). (2000). Psicologia comunitária: estudos atuais. Porto Alegre: Sulina.

Senra, C. M. G., \& Guzzo, R. S. L. (2012). Assistência social e psicologia: sobre as tensões e conflitos do psicólogo no cotidiano do serviço público. Psicologia \& Sociedade, 24(2), 293-299.

Silva, R. C. (1998). O trabalho do psicólogo em centros de saúde: algumas reflexões sobre as funções da psicologia na atenção primária à saúde (Tese de doutorado não-publicada). Universidade de São Paulo.

Yamamoto, O., \& Gouveia, V. V. (Orgs.). (2013). Construindo a Psicologia brasileira: desafios da Ciência e prática psicológica. São Paulo: Casa do Psicólogo.

Recebido: outubro 11, 2014

Aprovado: março 23, 2015 